\title{
How econometrics can help us understand the effects of climate change on crop yields: the case of soybeans.
}

\author{
Hildegart Ahumada ${ }^{\dagger}$ \\ Universidad Torcuato Di Tella
}

\author{
Magdalena Cornejo ${ }^{\ddagger}$ \\ Universidad Torcuato Di Tella and CONICET
}

\begin{abstract}
Climate econometrics is a new field which is providing a fruitful approach to give a rigorous basis for many hypotheses related to climate change. With this aim, this chapter illustrates how econometrics can help understand the effects of climate change on the time behavior of crop yields at a country-level scale. We discuss different issues which empirical studies should address such as the non-stationarity nature of climate variables, the exogeneity of the variables used for modelling crop yields, the existence of non-linearities, the presence of extreme events, disentangling short and dealing with long-run effects of climate change, and collinearities in a multivariate framework. The incorporation of new lands to production or the rise of crop yields on existing lands to meet increasing demand for food and energy may be threatened by global climate change. However, there are several factors that have reduced the harmful impacts of climate change: adaptation, trade, the declining share over time of agriculture in the economy and carbon fertilization. In particular, the $\mathrm{CO}_{2}$ fertilization effect should be taken into account for certain crops. As an example, we focus on soybeans in the main producer and exporter countries: Brazil and United States, and particularly in Argentina, as an interesting case of mitigation and adaptation processes due to global and local climate changes.
\end{abstract}

Key Words: climate change; econometrics; crop yields; soybeans; Argentina.

\footnotetext{
${ }^{\dagger}$ School of Government, Universidad Torcuato Di Tella, Argentina. hahumada@utdt.edu.

${ }^{\ddagger}$ School of Government, Universidad Torcuato Di Tella and CONICET, Argentina. mcornejo@utdt.edu
} 


\section{Introduction}

Worldwide population growth is expected to increase by over a third -or 2.2 billion peopleby 2050 according to the 2017 United Nations World Population Prospects revision. This projection poses an urgent need to increase agricultural production to meet global needs for food, animal feed and biofuel, by increasing the amount of agricultural land to grow crops, enhancing productivity on existing agricultural lands or both. The main challenge would be how to meet the increasing demand for food while protecting our natural resources.

Although the effects of climate change may imply incorporating new areas devoted to different crops, the possibility of extending lands to production or increasing crop yields on existing lands may be threatened by global climate change too. Crop production and yield are highly dependent on climate. Increases in temperature and changing patterns of rainfall associated to global and local climate changes may lead to a considerable decline in crop production. Also, extreme weather events such as droughts, heat or cold waves, and heavy rainfall leading to floods have increased since 1950 according to the Fifth Assessment Report of the Intergovernmental Panel on Climate Change (IPCC). An analysis of long-term and short-term weather events is needed in order to measure the effects of climate change on crop yields.

Agricultural production needs to adopt more efficient and sustainable production methods to lessen the negative effects of climate change and to better tailor policies seeking to promote sustainable growth in the agricultural sector.

Adaptation to climate variability and extreme events can help for reducing vulnerability to long-term climate change. However, the effects of climate change also need to be considered along with other evolving factors that affect agricultural production, such as changes in farming practices and technology as well as commodity or input prices. Quantifying these effects will provide important insights into how much to spend on mitigation and adaptation. Furthermore, understanding and estimating the effects of climate change will also help policymakers to develop mitigation and adaptation strategies.

Therefore, the aim of this chapter is to suggest how econometrics can help understand the effects of climate change on the time behavior of crop yields at a country-level scale. Indeed, climate econometrics provides an approach to give a rigorous basis for many hypotheses related to climate change. In this line, an accurate econometric strategy to model the effects of climate change on crop yields should be able to deal with, at least:

(i) the non-stationarity nature of climate variables;

(ii) exogeneity;

(iii) the existence of non-linearities;

(iv) the presence of extreme events;

(v) disentangling short and long-run effects of climate change;

(vi) collinearities in a multivariate framework. 
We focus on soybeans in the main producer and exporter countries: Brazil and United States, and particularly in Argentina, as an interesting case of mitigation and adaptation processes due to global and local climate changes.

The chapter is organized as follows. Section 2 reviews the empirical literature of the effects of climate change on crop yields. Section 3 describes the case of soybeans. Section 4 discusses the different empirical issues that should be accounted by an accurate econometric model. Finally, Section 5 concludes.

\section{The effects of climate change on crop yields}

Different approaches have been followed to study the effects of climate change on crop yields, many of them based on agronomic analysis. However, results are not conclusive about the effects of climate change, mainly due to the adaptation and mitigation strategies in agriculture that have been also implemented to alleviate its potential negative effects.

The negative effects of climate change are mainly associated to extreme high temperatures which are found to be harmful for crop growth (e.g. Chen et al. 2013). Crop yield losses on the hottest days drive much of the effect of temperature (Schlenker and Roberts 2009). In fact, many recent studies found that changes in temperature are more important than changes in rainfall, at least at the national and regional levels (Reilly and Schimmelpfennig 2000; Schlenker and Lobell 2010). Furthermore, crops are more sensitive to extremely high temperatures during the phases of the plant growth cycle (Auffhammer et al. 2012; Welch et al. 2010). Temperature extremes can be critical for reducing yields, especially if they coincide with the flowering stage of the crop (Wheeler et al. 2000). Burke and Emerick (2016) examine the effect of long-term changes in climate variables on yields using countylevel data in the United States. Their results indicate that the main crops in the U.S. -corn and soybeans- are significantly and negatively affected by long-term changes in extreme heat temperatures.

Nevertheless, there would be several factors that have reduced the harmful impacts of climate change: adaptation, trade, the declining share over time of agriculture in the economy and carbon fertilization. As stated by Nordhaus (2013, p.84) "one important mitigation factor for agriculture is carbon fertilization". The carbon (or $\mathrm{CO}_{2}$ ) fertilization effect is the phenomenon by which the increase of carbon dioxide in the atmosphere increases the rate of photosynthesis in plants. That is, the largest amount of carbon dioxide $\left(\mathrm{CO}_{2}\right)$ in the atmosphere, that has resulted from rising anthropogenic emissions, may have positive effects on the plants growth as they use carbon dioxide during photosynthesis. Carbon fertilization has a greater effect on plants with $\mathrm{C}_{4}$ and $\mathrm{C}_{3}$ photosynthesis systems (such as corn and soybeans, respectively), which can concentrate carbon dioxide onto reaction sites.

According to Nordhaus (2013) multiple field studies found that doubling atmospheric concentrations of $\mathrm{CO}_{2}$ would increase yields of rice, wheat and soybeans about 10-15 percent. For the Argentine case, Magrin et al. (2005), by using agronomic models, found that increases in yields corresponding to climate changes between 1930-60 and 1970-2000 were $38 \%$ in the case of soybeans. In a recent paper, Ahumada and Cornejo (2018) found that the median 
variations on $\mathrm{CO}_{2}$ concentrations in the atmosphere could have increased soybeans yields about 14\% during 1973-2015, all else equal. However, the carbon fertilization effect may not take place if other plant growth factors are severely limiting. Nutrient levels, soil moisture, water availability and other conditions must also be met. Gray et al. (2016) found that the intensification of drought eliminates the potential benefits of elevated dioxide for soybean.

Empirical studies should not ignore or underestimate the effects of adaptation measures as means for diminishing the adverse effects of climate change. Several adaptation measures such as shifting planting dates, rotating crops or developing new crop varieties have also been suggested and implemented for reducing the vulnerability from the potential negative impacts of climate change on crop yield and production (Lobell et al. 2008; Cohn et al. 2016).

Even if the focus is on studying the effects of climate change on crop yields, an econometric model should be developed within a multivariate framework. That is, other potential determinants of crop yields apart from climate (e.g. technological factors) should be also considered in the analysis.

\section{The case of soybeans}

In this section, we describe the case of soybeans as an interesting example of mitigation and adaptation processes to climate change, particularly in Argentina, the third worldwide producer and exporter.

The demand for oilseeds, and particularly for soybeans, is derived primarily from the commercial utilization of its sub-products, high-protein soybean meal for animal feed and soybean oil for edible and inedible uses. Non-traditional soybean uses such as bio-energy and bio-products are expected to increase rapidly and promise to boost prices due to increased global demand and higher value-added. Moreover, not only most renewable energy sources have minimal contributions to global warming emissions, in contrast to fossil fuels, but they also provide an alternative to the eventually reserves depletion.

Over the last decades, Brazil and Argentina's combined total soybean production has been greater than that of the United States (the world's top producer). According to the 2016/17 World Agricultural Supply and Demand Estimates of the U.S. Department of Agriculture, Brazil and Argentina account for almost $49 \%$ of the worldwide soybean production compared to the $34 \%$ of the U.S. production. Figure 1 shows the evolution of soybeans yield from 1961 to 2016 in Argentina, Brazil and United States. 
Figure 1. Soybeans yield (in $\mathrm{kg} / \mathrm{ha}$ )

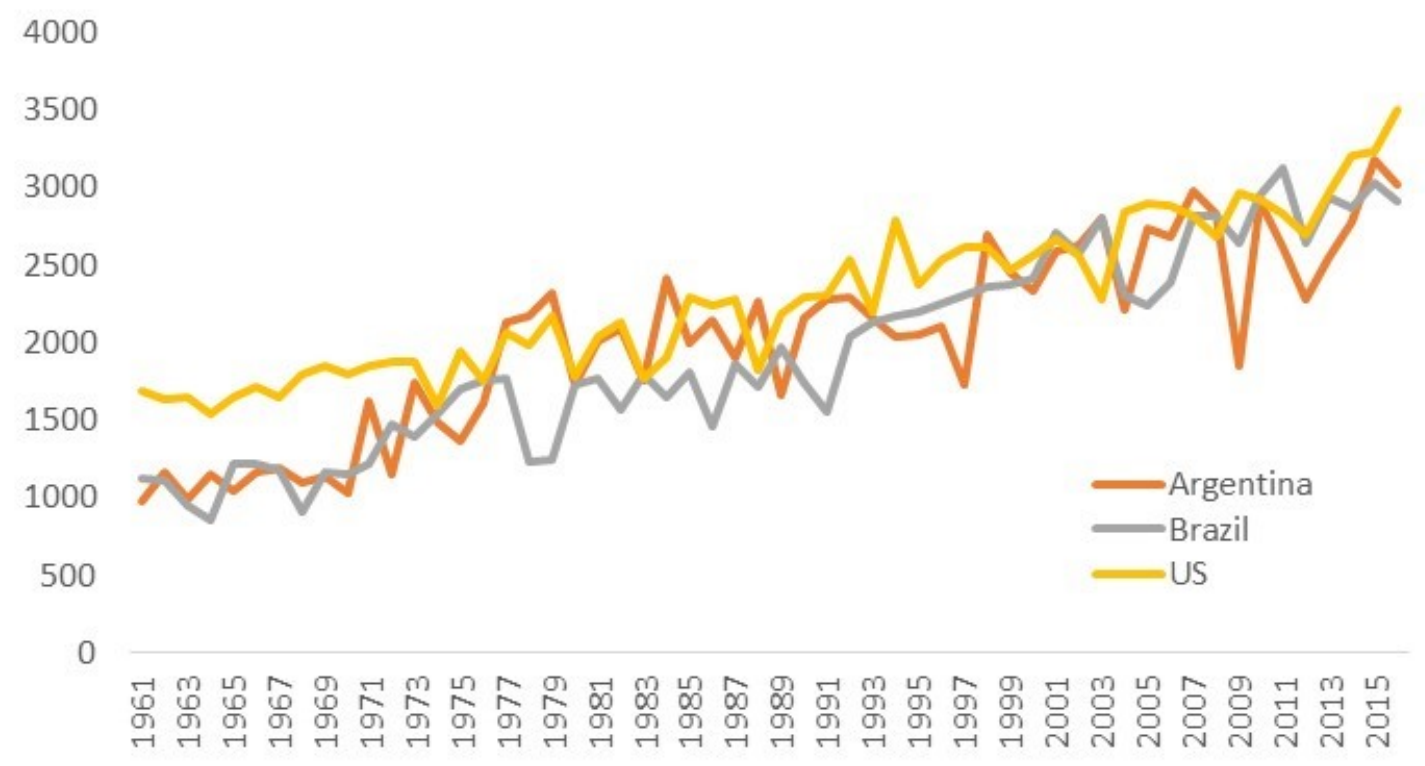

Source: Own elaboration using data from FAOSTAT.

A rigorous empirical approach should be able to deal with the upward behavior of soybean yields and, thus, with their potential non-stationarity (see Section 4.1 for a deeper analysis) to identify which variables are the long-run determinants responsible of their observed trend.

Soybeans are an interesting case to study the effect of climate change on crop yields. Crop production and yields are highly dependent on climate and, in fact, global climate change may threaten the incorporation of new lands to production or the increase of crop yields on existing lands. Climate changes and technological advances have shifted the main worldwide production areas to nowadays warmer latitudes (to the north in the Southern hemisphere and to the south in the Northern hemisphere).

Furthermore, new managerial practices have been introduced to increase crop yields and to adapt to climate change. For instance, no till practices have gained ground quickly in Argentina as an effective solution to the problem of soil erosion and the loss of nutrients and, thereby, it increases carbon sequestration, reduces costs and boosts productivity. The fastest adoption rates have been experienced in Argentina. According to AAPRESID, the Argentine No till Farmers Association, 93\% of the soybean area adopted the no-till system in the season 2016/17. The worldwide recognition of no-tillage farming as an effective sustainable system has spread no-till technology and other practices (e.g. crop rotation) to other areas and countries.

Other technological innovations include the use of genetically modified (GM) seeds. Soybean remains as the most adopted GM crop. According to the International Service for the Acquisition of Agri-biotech Applications (ISAAA) ${ }^{1}$ biotech soybean accounted for $50 \%$ of all the biotech crop area in the world in 2016. Commercially grown GM soybeans are concentrated in a few countries, mainly USA, Brazil and Argentina.

\footnotetext{
${ }^{1}$ ISAAA. 2016. Global Status of Commercialized Biotech/GM Crops: 2016. ISAAA Brief No. 52. ISAAA: Ithaca, New York.
} 
Therefore, given the technological advances experienced by this sector, empirical studies focused on studying the effect of climate change on crop yields should also control for mitigation and adaptation processes that are actually taking place in the agricultural sector.

\section{On the econometric modelling of soybean yields}

In this section, we discuss the different empirical issues that an econometric model of soybean yield determination should consider in order to measure the effects of climate change. Hsiang (2016) offers a wide revision of the different econometric methods that can be used to study the effect of climate change on social and economic outcomes, in general.

\subsection{Non-stationarity}

Variables may be classified according to their degree of time persistence into non-stationary or stationary. Non-stationarity is associated with the idea of long memory (high persistence) of past shocks on the behavior of a time series (e.g. crop yields). Such series could be stationary with a short time dependence -that is, they could exhibit a significant tendency to mean reversion- after first-differencing. In those cases, the series under study is said to have a unit root (a stochastic trend) or be integrated of first order, I(1).

This kind of behavior is generally compared with a typical model of deterministic trend to approximate the long run behavior of a series. As stated by Lobell (2009), the trend in crop yields results largely from improvements in technology and, thus, for most crops the technology trend can be approximated with a first order polynomial (a linear trend).

For the series of our interest, different unit root tests, as reported in Table 1, show that soybean yields can be represented as stationary around a deterministic linear trend. This trending behavior was also observed in Figure 1. Because of that, many studies remove deterministic trends before studying the effects of climate factors on yields (see for example Thomasz et al. (2016) in the Argentine case or Tao et al. (2008) in the Chinese case).

Furthermore, given the non-linear and non-stationary nature of crop yields, many detrending methods have been suggested to model them (see the comparison of detrending crop yield data techniques in Lu et al. 2017).

Table 1: Unit root tests, 1961-2016

\begin{tabular}{lccccccc}
\hline \hline Variable & trend & $k$ & ADF & $b$ & PP & $b$ & KPSS \\
\hline $\ln$ yield $^{A R G}$ & yes & 0 & $-5.49^{* * *}$ & 4 & $-5.77^{* * *}$ & 5 & $0.18^{* *}$ \\
$\ln$ yield $^{B R A}$ & yes & 0 & $-5.53^{* * *}$ & 5 & $-5.45^{* * *}$ & 2 & 0.08 \\
$\ln$ yield $^{U S A}$ & yes & 0 & $-7.66^{* * *}$ & 8 & $-8.03^{* * *}$ & 9 & 0.09 \\
$\Delta \ln$ yield $^{A R G}$ & no & 0 & $-14.29^{* * *}$ & 14 & $-23.52^{* * *}$ & 54 & $0.50^{* *}$ \\
$\Delta \ln$ yield $^{B R A}$ & no & 2 & $-7.93^{* * *}$ & 23 & $-21.34^{* * *}$ & 20 & 0.20 \\
$\Delta \ln$ yield $^{U S A}$ & no & 2 & $-7.48^{* * *}$ & 26 & $-30.83^{* * *}$ & 22 & $0.35^{*}$ \\
\hline Note: $k$ is the lag length selected by SIC, $b$ is the bandwidth using Bartlett kernel. \\
${ }^{*},{ }^{* *}$ y ${ }^{* * *}$ indicate significance at the $10 \%, 5 \%$ and $1 \%$ level, respectively. ADF \\
$=$ Augmented Dickey Fuller, PP = Phillips-Perron, KPSS = Kwiatkowski-Phillips- \\
Schmidt-Shin. A constant and a trend were included for level variables, otherwise \\
only a constant was considered.
\end{tabular}


Nonetheless, it should be noted that if the aim of an empirical study is to understand which drivers could be behind these observed trending behaviors, the long-run relationships between crop yields and their potential determinants should be studied assuming them as I(1) (the simplest long memory process) and testing their cointegration (if the linear combination of those I(1) variables is stationary). Cointegration implies that two or several variables with a persistent behavior have common stochastic trends and that they will show a tendency to move together in the long run. As stated by Juselius (2006, p.18) "the order of integration of a variable is not in general a property of an economic variable but a convenient statistical approximation to distinguish between the short run, medium run and long run variation in the data".

Moreover, a cointegration analysis could also be useful because it allows us to identify which variables move the equilibrium (the pushing forces) and which correct deviations from equilibrium (the pulling forces), that is, testing weak exogeneity as shown in sub-section 4.2. We will also be back on the long-run and short-run effects on crop yields in sub-section 4.5.

\subsection{Exogeneity}

Typically, in the literature, climate variables (e.g. temperature, rainfall, humidity, storms, among others) are considered exogenous when studying their effect on agriculture, that is, they are considered as given for explaining crop yields. Due to the assumption about exogeneity and randomness of climate in many economic applications, climate variables act as a "natural experiment" and, therefore, would allow the researcher to statistically identify the causal effect of a variable on an economic outcome of interest.

However, as Pretis (2017) warns, human activity (say, through deforestation) affects local and global climate and climate change, in turn, affects human activity (say, crop production or yields). Empirically, this implies that if we want to estimate the effect of humanity (in its multiple dimensions) on climate change and vice versa, it is necessary to evaluate the exogeneity of the variables within the economic-climate system to understand these interrelations in the long-run. The analysis of exogeneity is crucial to obtain rigorous empirical estimates before proposing a model on economic variables or on climate variables. That is, the estimates from a single equation model or a system model would be different depending on the variables exogeneity assumptions.

To estimate a model in which climate variables affect Argentine soybeans yields as expressed in Equation (1), that is, climate variables as explanatory variables (also known as conditioning variables) in a single equation model, the exogeneity assumption is crucial. However, once cointegration is found it is possible to evaluate exogeneity (see subsection 4.5 for the cointegration analysis). A weak exogenous variable influences the long-run path of other variables in the system and, at the same time, it is not influence by them. That is, the weak exogenous variable pushes to move the long-run relationship while the endogenous variable adjusts to maintain the equilibrium. To consistently estimate Equation (1) as a single-equation model, we need to assume that yields are the endogenous variable while global temperature anomalies (temp) and $\mathrm{CO}_{2}$ concentrations in the atmosphere $\left(\mathrm{CO}_{2}\right)$ are weakly exogenous. 


$$
\ln \text { yield }=\beta_{0}+\beta_{1} \text { temp }+\beta_{2} \ln \mathrm{CO}_{2}+u
$$

Furthermore, if those climate variables are found to be weakly exogenous, we can test for non Granger causality. ${ }^{2}$ A variable will Granger-cause (GC) another variable if past values of a variable (say, global temperature or $\mathrm{CO}_{2}$ ) contain information that helps predict another variable (say, soybeans yields). Thus, Granger causality is a statistical concept of causality based on the anticipation of variables.

Using data from 1973 to 2015, we estimated a climate system based on Argentine soybeans yields, global temperature anomalies and global $\mathrm{CO}_{2}$ concentrations in the atmosphere using two lags. Results, as shown in Table 2, indicate that both climate variables GC soybeans yields.

Table 2: Granger causality test, 1973-2015

\begin{tabular}{|c|c|c|}
\hline Hypothesis & Statistic & p-value \\
\hline $\ln$ yield does not GC temp & 5.31 & 0.07 \\
\hline $\ln$ temp does not GC yield & 9.20 & 0.01 \\
\hline $\ln$ yield does not $\mathrm{GC} \mathrm{CO}_{2}$ & 5.87 & 0.05 \\
\hline $\ln \mathrm{CO}_{2}$ does not $\mathrm{GC}$ yield & 7.27 & 0.03 \\
\hline $\ln$ temp does not $\mathrm{GC} \mathrm{CO}_{2}$ & 6.31 & 0.04 \\
\hline $\ln \mathrm{CO}_{2}$ does not $\mathrm{GC}$ temp & 0.05 & 0.97 \\
\hline
\end{tabular}

Using a significance level of $5 \%$, the test rejects the null hypothesis that global temperature and $\mathrm{CO}_{2}$ do not GC soybeans yields, but not vice versa. That is, on annual basis, climate variables (global temperature anomalies and $\mathrm{CO}_{2}$ concentrations) anticipate soybeans yields.

However, as a long run concept, weak exogeneity can give different results from those obtained analysis Granger causality. Ahumada and Cornejo (2018) found that all variables adjust to deviations from the long-run equilibria. This finding implies that climate variables are not weak exogenous which indicates that a system approach should be followed instead of estimating a single equation model.

Although this result may be unexpected at first sight, it may be properly interpreted when we take into account the effect of deforestation. The soybeans upward trend in Argentina, a behavior also shown by other soybean producers such as Brazil (see Figure 1), could have given incentives to the expansion of agriculture through the use of new lands coming from deforestation. Using data from NASA's Moderate Resolution Imaging Spectrometer (MODIS) on the Terra and Aqua satellites, Morton et al. (2006) have shown that in 2003, the peak year of deforestation in Matto Grosso (Brazilian state with the highest deforestation and soybean production rates), more than 20 percent of the state's forests were converted to cropland.

Deforestation contributes to global climate warming since it is responsible for not compensating the anthropogenic emissions of carbon dioxide to the atmosphere. Therefore, in this sense, we could think that global temperature anomalies and $\mathrm{CO}_{2}$ emissions may also adjust to deviations from the long-run in our estimated climate system.

\footnotetext{
${ }^{2}$ It should be noted that Granger causality is a different statistical concept which is not a necessary condition for weak exogeneity, but for strong exogeneity (Engle et al. 1983).
} 


\subsection{Non-linearities}

Linearity is usually a starting functional form of many econometric models although there are several routes to relax this assumption by including polynomial terms, asymmetries, thresholds, etc. Different climate variables may have non-linear relationships with crop yields.

Using different spatial panel econometric techniques, Chen et al. (2013) found nonlinearities and asymmetric relationships between yields and weather variables as it has been suggested in the literature. It is usually considered that the best predictor of crop yield is some measure of extreme heat during the growth period of the plant, considering a temperature threshold above $29^{\circ} \mathrm{C}$ or $30^{\circ} \mathrm{C}$ (Schlenker and Roberts 2009), depending on the analyzed crop. Furthermore, extreme high temperatures are harmful for crop growth, particularly during the phases of the growth cycle (Auffhammer et al. 2012; Welch et al. 2010). Therefore, the effect of temperature could be non-linear but with a threshold at certain high levels.

Using daily data of maximum temperature from 54 meteorological stations of the Argentine soybean production area from 1973 to 2015, Ahumada and Cornejo (2018) constructed different variables that measure the number of days in a year, during the growing phase of the crop (from December to April) in which the temperature exceeded a threshold of $28^{\circ} \mathrm{C}, 29^{\circ} \mathrm{C}$, $30^{\circ} \mathrm{C}$ or $31^{\circ} \mathrm{C}$. The maximum temperature of each meteorological station was weighted by its share in the total soybean planted area. Those weights were annually updated to account for the displacement of crop areas over time. The construction of those variables allow them to capture non-linearities in the relationships between yield and local temperature as it has been suggested in the literature. They found that 10 additional days of maximum temperature above $30^{\circ} \mathrm{C}$ during the growing season produce a decrease of $5 \%$ in soybean yields.

For the Chinese case, Tao et al. (2008) also found a negative relation between growing season maximum temperature and soybean yield. Although they do not address the possibility of a non-linear effect, soybean yield significantly decreased by $11.1 \%$ to $22.7 \%$ in the Shanxi province for each degree increase in growing season maximum temperature from 1979 to 2002 .

Furthermore, as shown in Figure 2, the relationship between soybean yields and $\mathrm{CO}_{2}$ concentration in the atmosphere (to measure the carbon fertilization effect) may not be always linear as in the Argentine case suggesting a second degree polynomial functional form. Data on atmospheric $\mathrm{CO}_{2}$ at Mauna Loa Observatory were obtained from the NOAA Earth System Research Laboratory. ${ }^{3}$

\footnotetext{
${ }^{3}$ The carbon dioxide data on Mauna Loa constitute the longest record of direct measurements of $\mathrm{CO}_{2}$ in the atmosphere.
} 
Figure 2. Soybeans yield and $\mathrm{CO}_{2}$ concentration relationship from 1961 to 2016 .
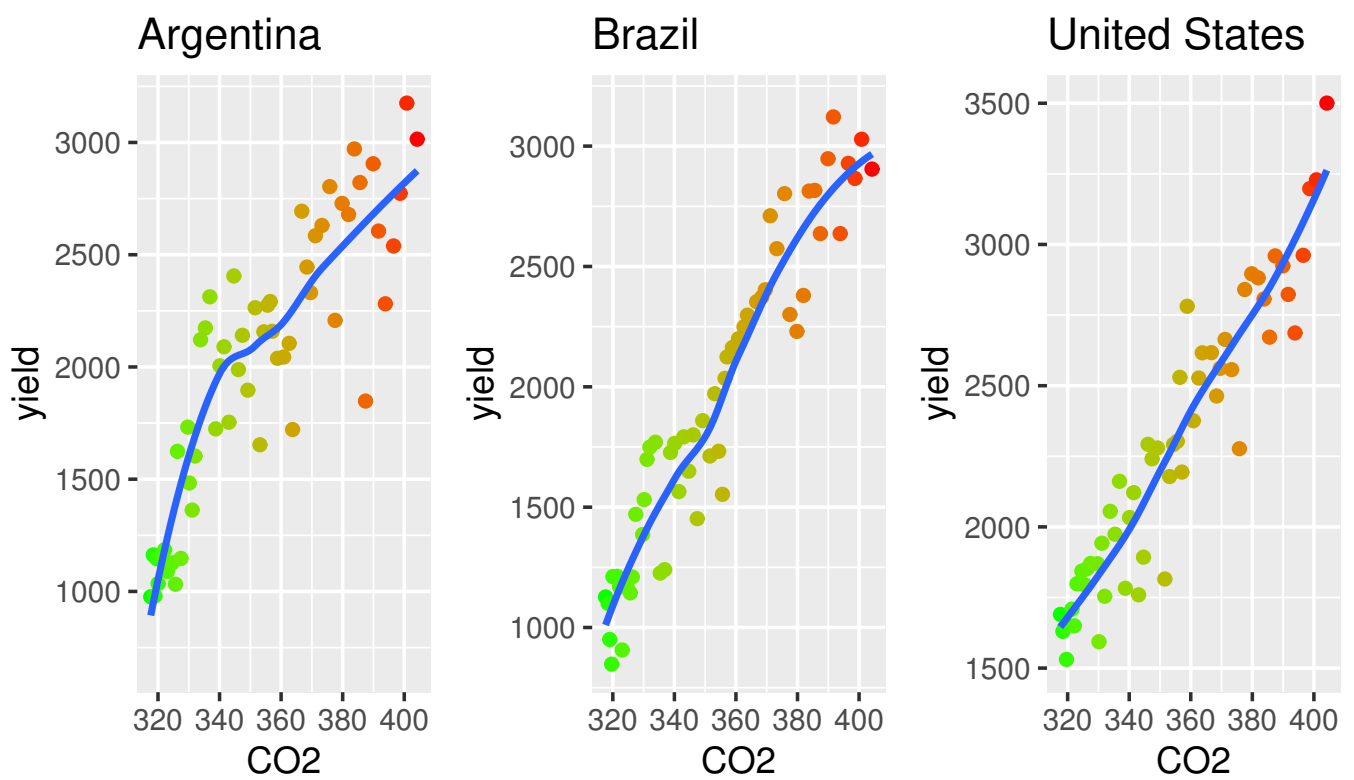

However, the figures and analysis were based on bivariate comparisons. In a multivariate framework, where other variables apart from yields and $\mathrm{CO}_{2}$ are also considered, the inclusion of other controls may capture the possible non-linearities and, consequently, a linear or loglinear functional form may be appropriate.

Many simulated crop yield responses studies evaluate crop yield response to elevated $\mathrm{CO}_{2}$ assuming hyperbolic behavior. Long et al. (2006) review the $\mathrm{CO}_{2}$ fertilization effects for the major $\mathrm{C}_{3}$ and $\mathrm{C}_{4}$ crops derived from enclosures, such as controlled environmental chambers, transparent field enclosures, or open-top chambers. The fertilization factors averaged across the $\mathrm{C}_{3}$ crops (rice, wheat and soybeans) are $24 \%$ for yield.

\subsection{Extreme events}

According to the Fifth Assessment Report of the Intergovernmental Panel on Climate Change (IPCC), extreme weather events such as droughts, heat or cold waves, and heavy rainfall leading to floods have increased since 1950. In this sense, variables that measure extreme weather events are of interest to include in the econometric models.

El Niño and La Niña are opposite phases that occur when the interaction between the Pacific Ocean and the atmosphere above it change from their neutral state in a cycle known as the El Niño-Southern Oscillation (ENSO). El Niño and La Niña events in the Pacific Ocean can be identified through the Southern Oscillation Index (SOI). The SOI, obtained from the Australian Bureau of Meteorology (BOM), is calculated using the pressure differences between Tahiti and Darwin. Sustained negatives values of SOI below -7 indicate El Niño episodes, while sustained positives values of SOI above +7 indicate La Niña episodes.

For the Argentine case, Ahumada and Cornejo (2018) found that an extreme event associated with La Niña episodes (droughts) decreases soybean yields between $1 \%$ and $2 \%$ during 1973-2015. 
Tack and Ubilava (2013) estimate the impact of both El Niño and La Niña on average corn yields using a U.S. county level panel spanning 55 years (1950-2005). They estimate the impact of El Niño (La Niña) on mean corn yields as the percentage change in the mean of the El Niño (La Niña) regime relative to the mean of the Neutral regime. The county-level impacts range from -24 to 33 percent for El Niño and from -25 to 36 for La Niña. The negative effect of El Niño is found for the corn belt region and, as a result, the impact turns positive as one migrates both to the East and West.

The effects of El Niño and La Niña on crop yields may be accentuated if global warming leads to an increase in the frequency and intensity of this type of events.

As Powell and Reinhard (2016) warn, extreme weather events are expected to increase worldwide and, given the local nature of some climate variables (particularly precipitations), the effects can also be measured at a local level. Using an unbalanced panel of 334 farms from 2002 to 2013, they analyze extreme weather events in the case of winter wheat throughout the Netherlands. They found that high temperature events and precipitation events significantly decrease yields.

\subsection{Disentangling short and long-run effects of climate change}

For series with persistent behavior, both stationary or integrated, which do not change much from period to period, it is possible to distinguish short run and long run effects.

For integrated variables (as explained in section 4.1), to obtain the long run effects we can test if the variables are cointegrated. Cointegration implies the existence of a linear combination of variables which is stationary when the variables in the relationship are nonstationary and integrated of equal order. Cointegrated variables are driven by the same persistent shocks and, thus, those variables have a common stochastic (and deterministic) trend, showing a tendency to move together in the long-run. As indicated by Juselius (2006), in multivariate cointegration analysis, all variables are represented as stochastic and a shock to one variable is transmitted to all other variables via the dynamics of the system until the system finds its new equilibrium position.

Once cointegration is found, an equilibrium correction model (ECM) can be estimated. This model encompasses differenced variables as well as the deviations from the long run or cointegrated relationship for integrated variables as expressed in Equation (3). There are several advantages of this formulation associated not only with avoiding multicollinearity typically present in time-series data (see also sub-section 4.6) but also allowing a more intuitive interpretation of the estimates disentangling short and long run effects.

Moreover, another advantage of using this approach is the invariance of the cointegration property to the extension of the information set (Juselius 2006). This property implies that once cointegration is found among a set of variables, the cointegration results will remain valid if more variables are added to the partial system, as the one we estimate below. In this sense, there would be no omitted variable effects present for cointegration when adopting this specific-to-general strategy.

Because of that, for the Argentine case, we start by estimating a partial system through 
a Vector Autoregressive (VAR) ${ }^{4}$ model between 1973 and 2015 among soybean yields, global temperature anomalies and $\mathrm{CO}_{2}$ concentrations in the atmosphere. This climate system also controls for two variables ${ }^{5}$ : La Niña Events and the number of days with maximum temperatures above $30^{\circ}$ during the growing season of the plant. Both variables negatively affect soybeans yields. ${ }^{6}$

Therefore, there is evidence from the climate system that one long-run relationship exists, as shown in Equation (2), in which all variables adjust to reach the long-run equilibrium. Equation (3) shows the climate ECM derived from Equation (2). Standard errors are reported in parentheses.

$$
\begin{gathered}
\ln \widehat{\text { yield }}=\underset{(2.75)}{11.94 \ln } \mathrm{CO}_{2}-\underset{(0.75)}{2.34 \mathrm{temp}} \\
\Delta \widehat{\ln \text { yield }}=\underset{(3.82)}{-15.97}-\underset{(0.06)}{0.27}\left[\ln \text { yield } t_{t-2}-\underset{(2.75)}{11.94 \ln } \mathrm{CO}_{2, t-2}-\underset{(0.75)}{\left.2.34 \mathrm{temp}_{t-2}\right]}\right. \\
-\underset{(0.004)}{0.01} \mathrm{Niña}_{t-1}-\underset{(0.002)}{0.008 m a x} 30_{t}-\underset{(0.09)}{0.61} \Delta \ln \text { yield }_{t-1}
\end{gathered}
$$

Equation (2) shows that global temperature anomalies (temp) and $\mathrm{CO}_{2}$ concentrations in the atmosphere are long-run determinants of Argentine soybean yields. To analyze the magnitude of estimated coefficients we can note that in this sample period, if the temperature changes as its median value during the sample $\left(0.06^{\circ} \mathrm{C}\right)$ soybean yields will decrease about $14 \%$ in the long run. However, as a possible mitigation effect due to that fertilization properties of $\mathrm{CO}_{2}$, yields will increase near $6 \%$ as a consequence of the median percentage variations of $\mathrm{CO}_{2}$ concentrations in the sample $(0.47 \%)$. This last result is known as the $\mathrm{CO}_{2}$ fertilization effect, as it has been previously described.

The estimated ECM indicates that $27 \%$ of the deviations from the long run equilibrium is corrected in two year.

As regards the climate variables short run effects, Equation (1) shows that apart from an autoregressive behavior of soybean yields, there are negative effects of La Niña events associated with droughts periods- and cumulated days of high temperature (above $30^{\circ} \mathrm{C}$ ). An extreme event associated with La Niña episodes decreases yields in 1\%, while 10 additional days of maximum temperatures above $30^{\circ}$ during the growing season produce a decrease of $8 \%$.

The estimated system in Equations (2) and (3) can be also used for prediction purposes. In this case, the constancy of the parameter estimates is a key issue. We can evaluate if parameters are unchanged by observing the recursive estimates of the coefficients. From an initial sample, the observations are added one by one until the last observation is included. Figure 3 shows that the coefficient estimates are inside the $95 \%$ confidence interval. Thus, for this simple model (from the partial system), parameter stability is not rejected. ${ }^{7}$

\footnotetext{
${ }^{4} \mathrm{~A}$ VAR model is a multivariate stochastic process model that can be used to capture the linear interdependences among the variables analyzed in the system. It generalizes the time series AR model.

${ }^{5}$ These variables were included unrestrictedly in the system, that is, outside the cointegration vector.

${ }^{6}$ The VAR model passes all diagnostic tests at traditional levels and included a linear trend in the long run since the variables can cointegrate but may have different deterministic trends. These results are not reported but can be obtained from the authors upon request.

${ }^{7}$ Given the goodness of fit that has been obtained.
} 
Figure 3. Recursive estimates ${ }^{8}$
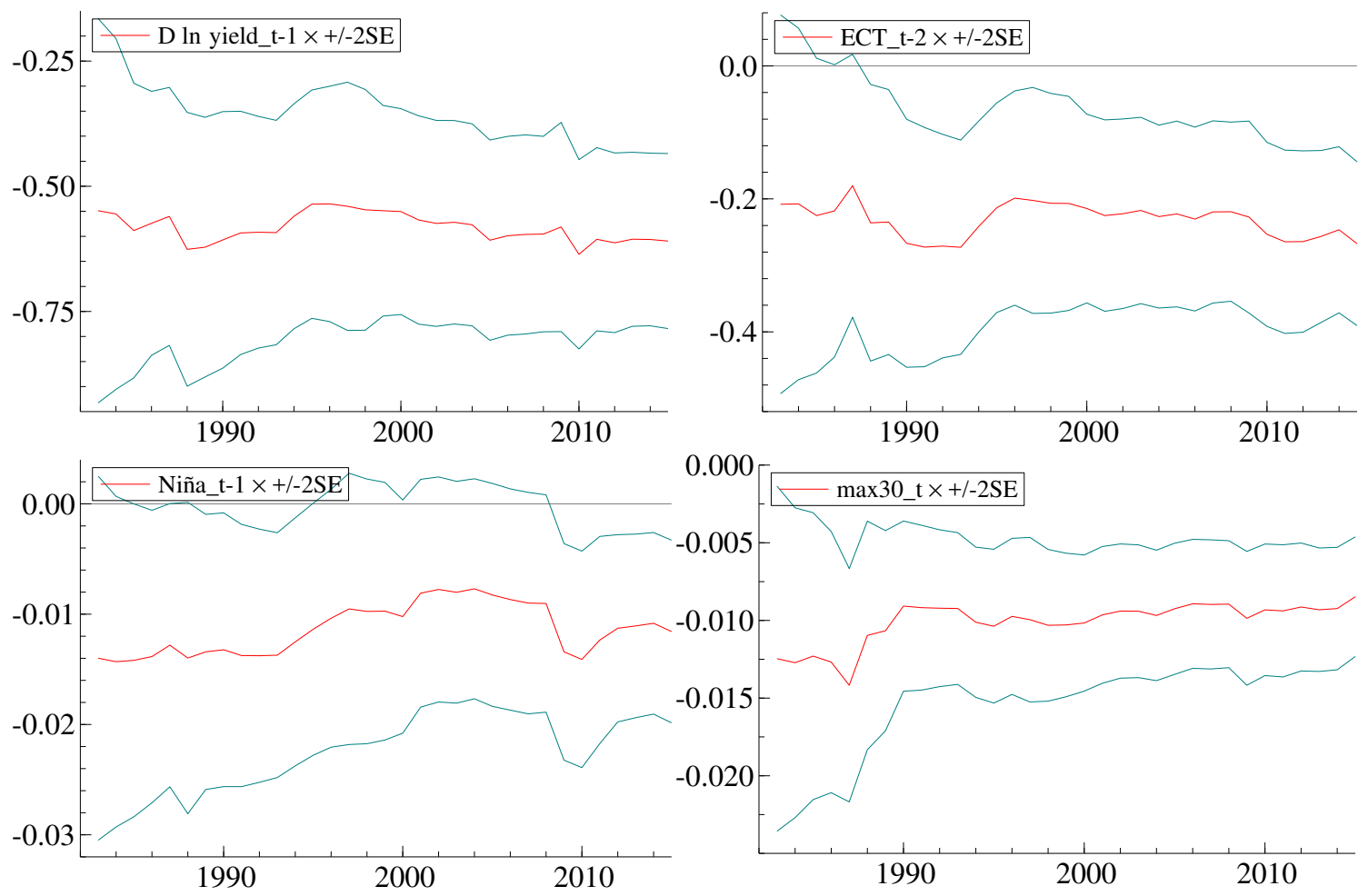

It should be noticed that we have also tested for other climate variables such as El Niño events and weather variables associated with excessive precipitations and floods, ${ }^{9}$ but they were found statistically insignificant. The greater importance of changes in temperature over changes in rainfall on crop yields was also found by Reilly and Schimmelpfennig (2000) and Schlenker and Lobell (2010).

This partial system estimation and the ECM do not consider the effect of other relationships such as the interaction between technology and climate. As an example, using data from 1973 to 2015 we found on cointegration relationship between global temperature anomalies (temp) and two technological variables: the adoption of new seed varieties (seeds) and the no-till adoption $(n o-t i l l)$. The adoption of new seed varieties is measured as the number of soybean varieties registered in United States, Brazil and Argentina (the three main worldwide producers of soybeans). The no-till adoption is measured as the proportion of no tilled cropland acres in Argentina.

In this cointegration relationship, which is reported in Equation (4), only the adoption of new seed varieties adjust to deviations from the long-run equilibria.

$$
\widehat{\operatorname{seed} s}=\underset{(0.74)}{2.13 t e m p}+\underset{(0.005)}{0.01} \text { no-till }
$$

The positive long-run effect of global temperature anomalies on the use of new modified seeds may indicate that adaptation processes to climate change are being undertaken in

\footnotetext{
${ }^{8} \mathrm{ECT}$ denotes the Error Correction Term, that is, the deviation from the long-run relationship.

${ }^{9}$ Those variables include: the variance coefficient, the Rainfall Gini Index, the Precipitation Concentration Index and the cumulative precipitation during the growing phase of the plant.
} 
the agricultural sector. According to these results, the potential negative effect of climate change on agricultural could have led producers to invest on technology in order increase their productions and crop yields. Moreover, the changes in managerial practices experienced in Argentina through the adoption of no till practices has also a positive effect on the use of new seeds. The incorporation of no-till technology does not only protect the soil from erosion caused by plowing, but it also requires new genetically modified (GM) seeds (such as herbicide-tolerant crops).

\subsection{Collinearities in a multivariate framework}

As it has been previously stated, in order to econometrically model the effect of climate change on crop yields, a multivariate framework should be used to control for and also to integrate different groups of determinants (climatic, technological or economic) that may affect crop yields (see, for example, Huang and Khanna 2010). However, collinearity is strongly present in time-series data that show trending behavior.

Auffhammer et al. (2013) indicate that many empirical studies do not take into account all relevant climate dimensions, and many of them are difficult to measure. Some works focus on studying the effect of a single climate variable (such as temperature or rainfall). Auffhammer and Schlenker (2014) warn that if a single climate variable is used as a regressor, this measure will be subject to confounding variation of other climate measures that are correlated with it and also affect the variable of interest. This approach can lead to a classic problem of bias due to omitted variables.

In the case of Argentina soybeans yields, we have found that global temperature anomalies and $\mathrm{CO}_{2}$ concentrations are not weakly exogenous (see sub-section 4.2). Thus, estimating a single-equation model may also result in different long-run coefficient estimations, even if cointegration is found. Equation (5) reports the coefficient and standard errors (in parentheses) obtained from a single-equation estimation not controlling for other climate variables, which are different from those reported in Equation (3) corresponding to a multivariate system estimation.

$$
\widehat{\ln \text { yield }}=\underset{(35.62)}{12.89}-\underset{(6.17)}{0.95} \ln \mathrm{CO}_{2}+\underset{(0.23)}{0.44 \text { temp }}+\underset{(0.03)}{0.008 \text { trend }}
$$

It should be noted that even controlling for a deterministic trend, when the conditioning variables are not weakly exogenous or, in particular, when we do not control for other potential determinants such as Niña events or $\max 30$ as the system estimation did, global temperature anomalies have a positive long-run coefficient while $\mathrm{CO}_{2}$ concentrations have a negative coefficient. Control variables play a key role in a regression analysis as they reduce the effect of confounding variables and avoid misleading conclusions. As an example, the result obtained in Equation (5), contrary to what we have found following a multivariate approach which also controls for other variables, will indicate that increases in global temperature anomalies will rise soybeans yield while increases in $\mathrm{CO}_{2}$ concentration will decrease soybeans yields.

In order to consistently estimate the long-run coefficient, a partial system approach can be 
followed as discussed in Juselius (2006). To take into account different potential determinants and to avoid collinearities, sub-systems of long-run relationships due to climate, technological and economic factors can be estimated and then evaluated by encompassing of the different ECM representations (as in Ahumada and Cornejo 2018). The aim of testing encompassing is to address if crop yields adjust to one or several long-run relationships.

\section{Final remarks}

The aim of this chapter has been to illustrate how econometrics can help understand the effects of climate change on the time behavior of crop yields at a country-level scale for the main producers and exporter of soybeans. We have focused on this crop as a particular case of adaptation and mitigation, with emphasis on the Argentine experience.

Climate econometrics provides an approach to give a rigorous basis for many hypotheses related to climate change. In this line, we have discussed the different empirical issues that an accurate econometric strategy should address in order to model the effects of climate change on crop yields: the non-stationarity nature of climate variables; the exogeneity of the variables used for modelling crop yields; the existence of non-linearities; the presence of extreme events; disentangling short and long-run effects of climate change and collinearities in a multivariate framework.

Using data from 1973 to 2015, results obtained from a multivariate system estimation indicate that global temperature has a long run negative effect of Argentine soybeans yields. Furthermore, we have also found negative short-run effects associated to La Niña events and high temperatures during the growing season of the plant. However, those global and local warming negative effects are partially mitigated through the $\mathrm{CO}_{2}$ fertilization effect.

The estimation of this model have shown that a multivariate framework, including Niña events and the $30^{\circ} \mathrm{C}$ threshold in temperature, and adopting a partial system instead of a single equation approach give different results with a clearer interpretation of the estimates. It is worth noting that, apart from the long run linear effect of global temperature anomalies, we found a short run non-linear effect derived from the number of days in which the maximum temperature exceeded $30^{\circ} \mathrm{C}$ during the growing season of the plant.

So far, we have only focused on climate variables. However, when there are other potential determinants as in the case of crop yields, the econometric model should encompass other drivers like technology or economic factors. This appears as a future route of research in particular when technology should be analyzed as an adaptation response to climate change too. 


\section{References}

Ahumada, H. and Cornejo, M. (2018), 'Are soybean yields getting a free ride from climate change? Evidence from Argentine time series'.

Auffhammer, M., Hsiang, S. M., Schlenker, W. and Sobel, A. (2013), 'Using weather data and climate model output in economic analyses of climate change', Review of Environmental Economics and Policy 7(2), 181-198.

Auffhammer, M., Ramanathan, V. and Vincent, J. R. (2012), 'Climate change, the monsoon, and rice yield in India', Climatic Change 111(2), 411-424.

Auffhammer, M. and Schlenker, W. (2014), 'Empirical studies on agricultural impacts and adaptation', Energy Economics 46, 555-561.

Burke, M. and Emerick, K. (2016), 'Adaptation to climate change: Evidence from US agriculture', American Economic Journal: Economic Policy 8(3), 106-40.

Chen, S., Chen, X. and Xu, J. (2013), 'Impacts of climate change on corn and soybean yields in China', AAEA 83 CAES Joint Annual Meeting .

Cohn, A. S., VanWey, L. K., Spera, S. A. and Mustard, J. F. (2016), 'Cropping frequency and area response to climate variability can exceed yield response', Nature Climate Change $\mathbf{6}(6), 601$.

Engle, R. F., Hendry, D. F. and Richard, J.-F. (1983), 'Exogeneity', Econometrica: Journal of Econometric Society pp. 277-304.

Gray, S. B., Dermody, O., Klein, S. P., Locke, A. M., Mcgrath, J. M., Paul, R. E., Rosenthal, D. M., Ruiz-Vera, U. M., Siebers, M. H. and Strellner, R. (2016), 'Intensifying drought eliminates the expected benefits of elevated carbon dioxide for soybean', Nature Plants $\mathbf{2}(9), 16132$.

Hsiang, S. (2016), 'Climate econometrics', Annual Review of Resource Economics 8, 43-75.

Huang, H. and Khanna, M. (2010), 'An econometric analysis of US crop yield and cropland acreage: implications for the impact of climate change', AAEA Annual Meeting pp. 25-27.

Juselius, K. (2006), The Cointegrated VAR Model. Methodology and Applications, Oxford University Press, Oxford.

Lobell, D. B. (2009), Crop Response to Climate: Time-Series Models, in D. B. Lobell and M. Burke, eds, 'Climate change and food security: adapting agriculture to a warmer world', Springer Science \& Business Media.

Lobell, D. B., Burke, M. B., Tebaldi, C., Mastrandrea, M. D., Falcon, W. P. and Naylor, R. L. (2008), 'Prioritizing climate change adaptation needs for food security in 2030', Science 319(5863), 607-610. 
Long, S. P., Ainsworth, E. A., Leakey, A. D., Nösberger, J. and Ort, D. R. (2006), 'Food for thought: lower-than-expected crop yield stimulation with rising co2 concentrations', Science 312(5782), 1918-1921.

Lu, J., Carbone, G. J. and Gao, P. (2017), 'Detrending crop yield data for spatial visualization of drought impacts in the united states, 1895-2014', Agricultural and Forest Meteorology pp. 196-208.

Magrin, G. O., Travasso, M. I. and Rodríguez, G. R. (2005), 'Changes in climate and crop production during the 20th century in Argentina', Climatic Change 72(1-2), 229-249.

Morton, D. C., DeFries, R. S., Shimabukuro, Y. E., Anderson, L. O., Arai, E., del Bon Espirito-Santo, F., Freitas, R. and Morisette, J. (2006), 'Cropland expansion changes deforestation dynamics in the southern Brazilian Amazon', Proceedings of the National Academy of Sciences 103(39), 14637-14641.

Nordhaus, W. D. (2013), The climate casino: Risk, uncertainty, and economics for a warming world, Yale University Press.

Powell, J. P. and Reinhard, S. J. (2016), 'Measuring the effects of extreme weather events on yields', Climatic Change 12(1), 69-79.

Pretis, F. (2017), 'Exogeneity in climate econometrics'.

Reilly, J. and Schimmelpfennig, D. (2000), 'Irreversibility, uncertainty, and learning: portraits of adaptation to long-term climate change', Climatic Change 45(1), 253-278.

Schlenker, W. and Lobell, D. B. (2010), 'Robust negative impacts of climate change on African agriculture', Environmental Research Letters 5(1), 014010.

Schlenker, W. and Roberts, M. J. (2009), 'Nonlinear temperature effects indicate severe damages to us crop yields under climate change', Proceedings of the National Academy of Sciences 106(37), 15594-15598.

Tack, J. B. and Ubilava, D. (2013), 'The effect of El Niño Southern Oscillation on US corn production and downside risk', Climatic Change 121(4), 689-700.

Tao, F., Masayuki Yokozawa, J. L. and Zhang, Z. (2008), 'Climate-crop yield relationships at provincial scales in China and the impacts of recent climate trends', Climate Research 38(1), 83-94.

Thomasz, E. O., Casparri, M. T., Vilker, A. S., Rondinone, G. and Fusco, M. (2016), 'Medición económica de eventos climáticos extremos en el sector agrícola: el caso de la soja en Argentina', Revista de Investigación en Modelos Financieros 4.

Welch, J. R., Vincent, J. R., Auffhammer, M., Moya, P. F., Dobermann, A. and Dawe, D. (2010), 'Rice yields in tropical/subtropical Asia exhibit large but opposing sensitivities to minimum and maximum temperatures', Proceedings of the National Academy of Sciences 107(33), 14562-14567. 
Wheeler, T. R., Craufurd, P. Q., Ellis, R. H., Porter, J. R. and Prasad, P. V. (2000), 'Temperature variability and the yield of annual crops', Agriculture, Ecosystems $\mathcal{G}$ Environment 82(1-3), 159-167. 